\title{
Efficient photo- and electroluminescence by trap states passivation in vacuum- deposited hybrid perovskite thin films
}

Benedikt Dänekamp ${ }^{\dagger}$, Nikolaos Droseros ${ }^{\ddagger}$, Francisco Palazon, Michele Sessolo ${ }^{\dagger, *}$, Natalie Banerji ${ }^{\ddagger}$, Henk J. Bolink ${ }^{\dagger}$

†Instituto de Ciencia Molecular, Universidad de Valencia, C/ Catedrático J. Beltrán 2, 46980

Paterna (Valencia), Spain

Department of Chemistry and Biochemistry, University of Bern, Freiestrasse 3, CH-3012 Bern, Switzerland

\begin{abstract}
Methylammonium lead iodide (MAPI) has excellent properties for photovoltaic applications, although it typically shows low photoluminescence quantum yield (PLQY). Here we report on vacuum-deposited MAPI perovskites obtained by modifying the MAI to $\mathrm{PbI}_{2}$ ratio during vacuum deposition. By studying the excitation density dependence of the photoluminescence lifetime, a large concentration of trap states was deduced for the stoichiometric MAPI films. The use of excess MAI during vacuum processing is capable of passivating these traps, resulting in luminescent films which can be used to fabricate planar LEDs with quantum efficiency approaching $2 \%$.
\end{abstract}

KEYWORDS: perovskites, light-emitting diodes, vacuum deposition, passivation, stoichiometry 


\section{INTRODUCTION}

Hybrid lead halide perovskites are very interesting semiconductors for light-emitting diodes (LEDs), as they could meet the requirements to develop inexpensive and energy-efficient light sources. ${ }^{1-3}$ The low cost of the precursors and the possibility of easy and low temperature processing makes them potential competitors with LEDs prepared from inorganic crystalline semiconductors, as these require high temperature and complex manufacturing methods. Hybrid lead halide perovskite LEDs exhibit a narrow emission bandwidth easily tunable over the visible spectrum, leading to a high color purity. The type of halide employed in the perovskite has the strongest effect on the bandgap, i.e. methylammonium lead halide perovskites $\mathrm{MAPbX}_{3}$ with $\mathrm{X}=$ $\mathrm{Cl}^{-}, \mathrm{X}=\mathrm{Br}^{-}$, or $\mathrm{X}=\mathrm{I}^{-}$have bandgaps of approximately $3.1 \mathrm{eV}, 2.3 \mathrm{eV}$ and $1.6 \mathrm{eV}$, respectively. ${ }^{4}$ The bandgap can be further tuned by mixing the three halides in different ratios. ${ }^{5-6}$ As the wide bandgap perovskites containing $\mathrm{Cl}^{-}$and $\mathrm{Br}^{-}$emit in the visible range of the spectrum and show larger exciton binding energies, they have been predominantly investigated for LEDs. ${ }^{7}$ On the other hand, $\mathrm{MAPbI}_{3}$ has excellent properties for photovoltaic (PV) applications, such as the long carrier diffusion length, balanced hole and electron mobility, low trap density and free carrier generation at room temperature. ${ }^{8-12}$ The latter derives from a low exciton binding energy, reported to be within the $2-60 \mathrm{meV}$ range, ${ }^{13-15}$ which is beneficial for photovoltaics. Furthermore, most $\mathrm{MAPbI}_{3}$ perovskites show low photoluminescence quantum yield (PLQY), as the monomolecular trap-mediated recombination dominates at low excitation fluence. ${ }^{10,16-17}$ This means that at low current density, perovskite LEDs based on pure polycrystalline MAPI are rather inefficient. Strategies to overcome this limitation involve the use of quasi-2D perovskite structures to efficiently harvest charge carriers to the lowest-bandgap emitting material, the use of

nanostructured perovskite thin films or through passivating agents. ${ }^{18-20}$ An alternative way to 
enhance the photoluminescence of perovskites is the use of an excess of methylammonium iodide, which has been shown to improve the photo- and electroluminescence as it leads to smoother, trapfree films when processed from solutions. ${ }^{21-23}$ In solution-processed $\mathrm{MAPbBr}_{3}, \mathrm{a} \mathrm{MABr} / \mathrm{PbBr}_{2}$ molar ratio > 3 can lead to the formation of nanocrystals embedded in a MABr-rich matrix, with enhances the PLQY ${ }^{24}$ In MAPI films, an excess of MAI was found to cause brighter PL intensities and longer PL lifetimes both within the grains and at the grain boundaries, attributed to the passivation of the halide vacancies. ${ }^{25}$ The initial reports on vacuum-deposited MAPI thin films also used an excess of MAI, however an annealing step was used in order to promote the perovskite formation and the elimination of excess cation. ${ }^{26}$ Hence, the effect of resilient MAI content in vacuum deposited perovskite films and its effect on the luminescent properties of the materials is unknown. Here we report on vacuum-deposited MAPI perovskites obtained by modifying the MAI to $\mathrm{PbI}_{2}$ ratio during vacuum deposition by adjusting the respective sublimation rates without a post-deposition annealing step. These materials exhibit enhanced photoluminescent properties and, when incorporated into planar LEDs, lead to external quantum efficiency (EQE) approaching $2 \%$.

The MAPI films were prepared by adjusting the ratio of the MAI and $\mathrm{PbI}_{2}$ precursors. The ratios of these components were varied by modifying the deposition rate of $\mathrm{PbI}_{2}$ while maintaining the MAI deposition rate fixed during the dual-source deposition process. These ratios were determined from the calibrated quartz crystal microbalance sensor readings during the deposition process. Three different perovskite emitting layers were deposited with the MAI:PbI 2 deposition rate ratios of $1: 1,3: 1$ and $6: 1$. 

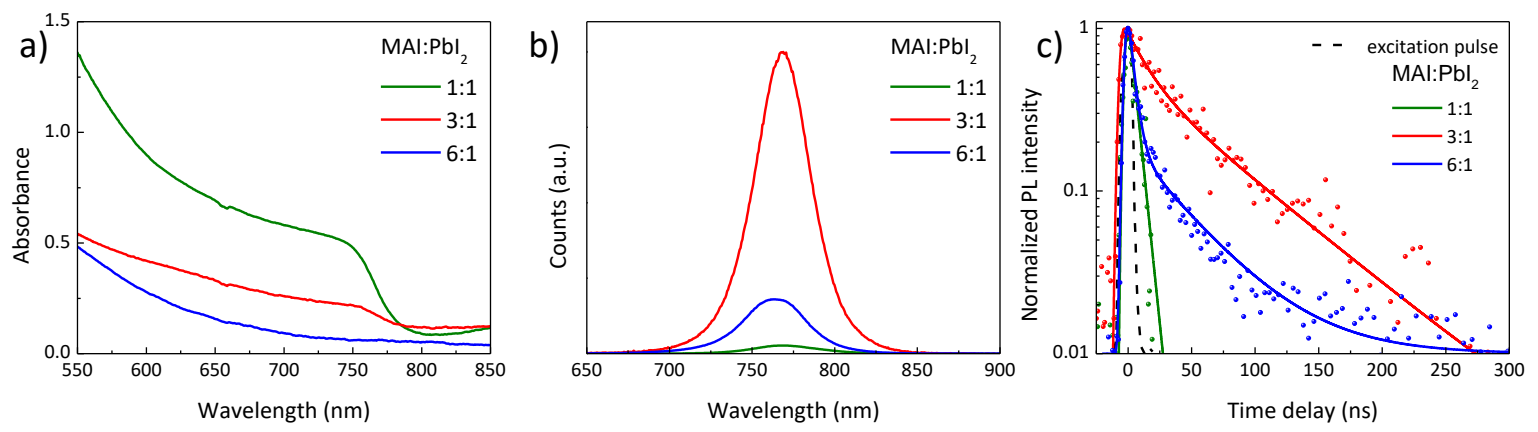

Figure 1. a) Absorption for the perovskite film series after exposure to air. b) PL spectra for the same compounds recorded under excitation with a $515 \mathrm{~nm}$ continuous wave laser with an irradiance of $300 \mathrm{~mW} / \mathrm{cm}^{2}$. c) PL dynamics of the three different MAPI films after exposure to air, monitored at the wavelength of their maximum intensity, each normalized to its maximum PL intensity. The films were excited at $520 \mathrm{~nm}$ with an excitation density of $5 \cdot 10^{17} \mathrm{~cm}^{-3}$.

The as-deposited 1:1 MAPI films showed the characteristic optical absorption for this particular perovskite compound, with an onset at $780 \mathrm{~nm}$ and intense absorbance throughout the visible range (Figure 1a). On the other hand, the optical absorption spectra of the perovskite films produced with MAI excess show a much lower absorbance, with the band-to-band absorption essentially vanishing in the case of the 6:1 compound (Figure S2). Interestingly, upon exposure to air, the absorption spectrum of the 3:1 perovskite progressively evolves showing the clear band-to-band transition at about $780 \mathrm{~nm}$ and reaching stable optical characteristics after approximately 20 minutes (see Figure $1 \mathrm{~b}$ and S2c). The effect of atmosphere on the perovskite growth and stability has been previously investigated. While a long exposure of perovskite films to ambient conditions usually leads to degradation and hence poorly performing devices, a controlled exposure during different processing steps can be beneficial. ${ }^{27-28}$ Methylammonium halides are very hygroscopic, 
favoring the penetration of water into the perovskite film. Water preferentially hydrates/partially re-dissolve the organic cations, allowing a reorganization of the material and promoting its recrystallization. ${ }^{29-31}$ This is most likely the mechanism responsible for the evolution of the absorption spectrum observed here, in view of the very high MAI content used in our films. Figure S3 shows the normalized photoluminescence spectrum of the perovskite film produced with 3:1 MAI:PbI ${ }_{2}$ before and after exposure to air for 30 minutes. The spectrum of the unexposed film is unsymmetrical and can be deconvoluted using two Gaussian functions (Figure S4), one centered at $747 \mathrm{~nm}$ and a second, lower intensity component at $712 \mathrm{~nm}$. This blue-shifted component is likely associated with an increased disorder in the material, ${ }^{32-33}$ as also observed by XRD and SEM for perovskites with excess MAI (see below). The high energy component eventually disappears after exposure to air, when a narrow PL signal with full width at half maximum (FWHM) of 40 $\mathrm{nm}$ and maximum intensity at $769 \mathrm{~nm}$ is observed. The latter corresponds to the expected bandgap energy for MAPI thin films (about 1.6 eV). A similar evolution of the PL spectra was observed for the perovskite films with the 6:1 ratio. Importantly, the absolute PL intensity increases after air exposure for the sample with 3:1 $\mathrm{MAI}_{\mathrm{PbI}} \mathrm{I}_{2}$ ratio. The photoluminescence decay dynamics were recorded (Figure 1c) and analyzed either with a single exponential function for the case of the 1:1 perovskite or by a double exponential for the case of the samples with excess MAI. The average lifetime was estimated using the following expression:

$$
\text { (1) }\langle\tau\rangle=\frac{\sum_{i}^{1,2} a_{i} \tau_{i}}{\sum_{i}^{1,2} a_{i}}
$$

where $\mathrm{i}=1$ for the $1: 1$ compound and $\mathrm{i}=2$ for those with higher MAI content. The perovskite with 3:1 MAI:PbI $\mathrm{Pas}_{2}$ a short PL lifetime of $\tau_{1}=5.7 \mathrm{~ns}$ and the average lifetime for the 6:1 perovskite films is slightly longer, $\langle\tau\rangle=13.5 \mathrm{~ns}\left(\tau_{1}=3.3 \mathrm{~ns}, \tau_{2}=26 \mathrm{~ns}\right)$. Interestingly, the average 
lifetime substantially increases for the films that where produced with a MAI:PbI 2 ratio of 3:1, to $\langle\tau\rangle=34.4 \mathrm{~ns}\left(\tau_{1}=13.7 \mathrm{~ns}, \tau_{2}=47 \mathrm{~ns}\right)$, thus contributing to their increased PLQY. The X-ray diffraction (XRD, Figure 2) for the film series was collected using Bragg-Brentano configuration to enhance the signal-to-noise ratio. The perovskite films were exposed 30 minutes to ambient atmosphere before the measurements and hence are treated the same way as the layers used for photo- and electroluminescence studies.
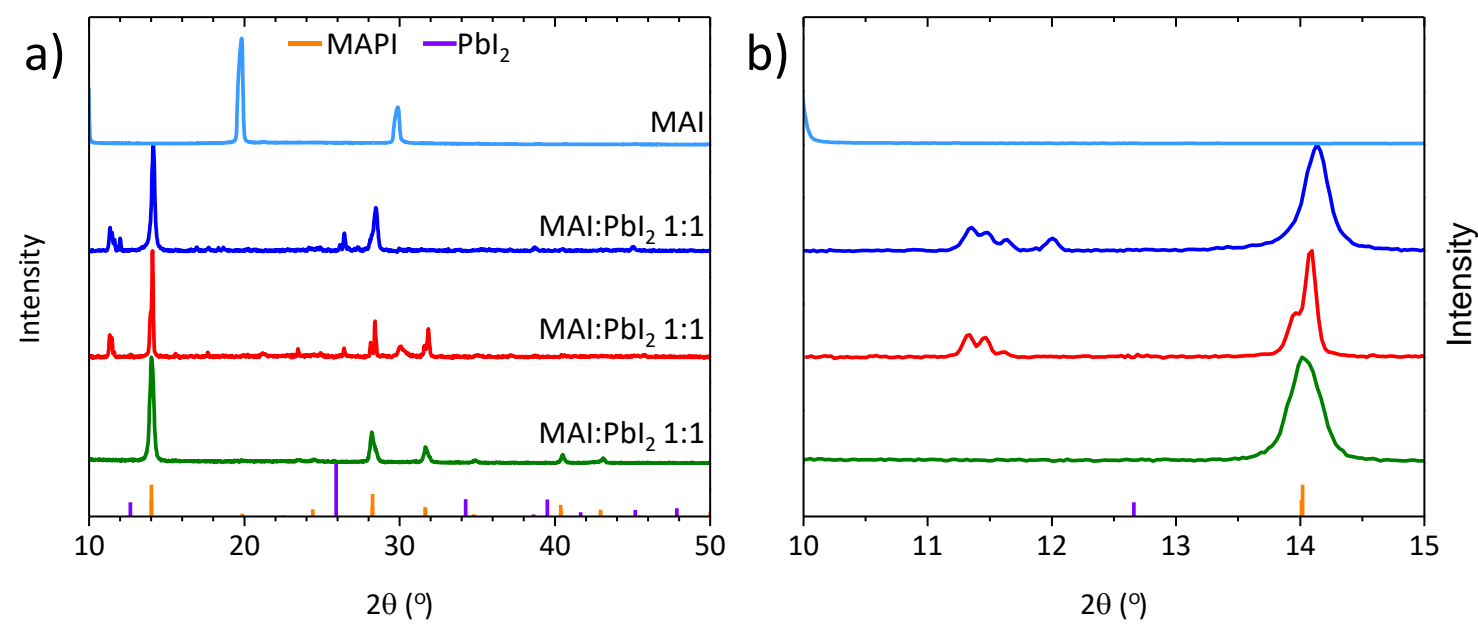

Figure 2. a) XRD patterns of the three different perovskite films with increasing MAI content and for a pure vacuum deposited MAI film. Reference patterns for MAPI and $\mathrm{PbI}_{2}$ are also included (ICSD collection codes 250735 and 68819, respectively). b) Zoom of the diffraction patterns in the $10^{\circ} \leq 2 \theta \leq 15^{\circ}$ range, highlighting the presence of structured reflections for excess-MAI perovskite films.

The XRD patterns show the characteristic tetragonal perovskite peaks at $14.02^{\circ}$ and $28.25^{\circ}$, corresponding to the (100) and (200) reflections, for all film stoichiometries. We noticed that when a large excess of MAI is used, the peak at $36.68^{\circ}$ (corresponding to a combination of the (012) and 
(021) reflections) is missing, suggesting a different orientation of the material. Importantly, for excess MAI-films, we identified weak diffraction signals at low angle $\left(11-12^{\circ}\right)$. These structured reflections cannot directly be ascribed to MAI, as they are not observed for the pure MAI films deposited in our setup (Figure 1a-b). However, they have been reported in the literature for MAPI films prepared from MAI-excess precursors and were attributed to the formation of lowdimensional perovskite species. ${ }^{34}$ The structural changes observed by XRD are reflected in the surface morphology of the films (Figure S1). In particular, only the stoichiometric MAPI shows a typical polycrystalline morphology, whereas the films with a MAI excess appear composed of large agglomerates without any well-defined grain structure.
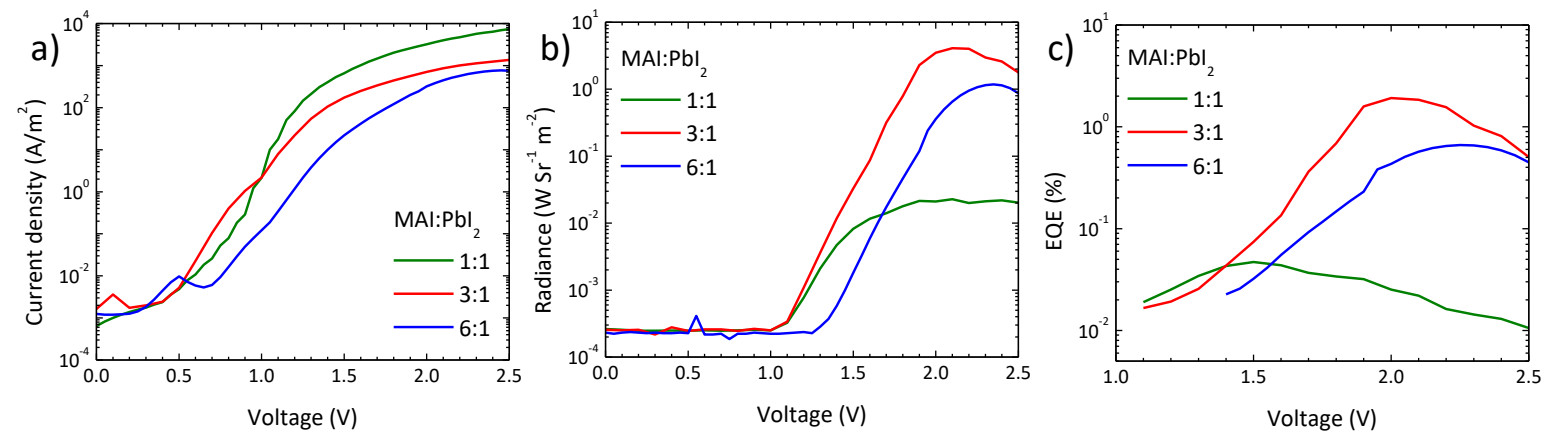

Figure 3. Optoelectronic characterization of MAPI LEDs with different $\mathrm{MAI} / \mathrm{PbI}_{2}$ ratios: a) current density, b) radiance and c) external quantum efficiency (EQE) vs. applied voltage.

The MAPI film series was used as the emissive layer in planar diodes with organic semiconductors as the charge transport materials. The emissive layer consisted of a $320 \mathrm{~nm}$ thick MAPI film exposed to air for 30 minutes, which was sandwiched in between a $10 \mathrm{~nm}$ thick hole transport (electron blocking) and electron transport (hole blocking) layers, referred to as HTL and ETL, 
respectively. The HTL consisted of a derivative of arylamine, N4,N4,N4",N4"'-tetra([1,1'biphenyl]-4-yl)- [1,1':4',1"'-terphenyl]-4,4"-diamine (TaTm) while the fullerene $\mathrm{C}_{60}$ was used as the ETL. In between the electrodes and the intrinsic HTL and ETL, we deposited $40 \mathrm{~nm}$ thick films with the same materials but doped in order to enhance the conductivity and hence the carrier injection. For the TaTm we used 2,20-(perfluoronaphthalene-2,6- diylidene) dimalononitrile ( $\mathrm{F}_{6}$ TCNNQ) as the organic dopant whereas for the $\mathrm{C}_{60}$ ETL, N1,N4-bis(tri-ptolylphosphoranylidene)- benzene-1,4-diamine (PhIm) was used. The stack was fully evaporated in an n-i-p configuration on pre-patterned ITO with gold as the reflective top contact. Detailed experimental conditions can be found in the Supplementary Information. The diodes were characterized in forward bias and the current density and radiance were measured as a function of driving voltage (Figure 3a-b). The current density starts to rise above $0.5 \mathrm{~V}$, and the current injection $>1 \mathrm{~V}$ is inversely proportional to the amount of MAI incorporated into the active layer. This might be expected considering the larger amount of excess material and reduced crystallinity in films with MAI excess, as also observed by XRD and SEM. The electroluminescence is detected at voltages as low as $1.1 \mathrm{~V}$ for the devices containing 1:1 and 3:1 perovskites, and at slightly higher voltage $(>1.3 \mathrm{~V})$ for the $6: 1$ compound. Interestingly, the highest power output was recorded for the LEDs based on non-stoichiometric compounds, with device employing the perovskite with MAI: $\mathrm{PbI}_{2}$ ratio of 3:1 reaching a maximum radiance of $4.1 \mathrm{~W} \cdot \mathrm{Sr}^{-1} \cdot \mathrm{m}^{-2}$, more than two orders of magnitude higher compared to the reference $1: 1$ device $\left(2.3 \cdot 10^{-2} \mathrm{~W} \cdot \mathrm{Sr}^{-1} \cdot \mathrm{m}^{-2}\right)$. The associated EQE is $1.92 \%$ for $3: 1 \mathrm{MAI}: \mathrm{PbI}_{2}$ compound as opposed to a maximum value of $0.05 \%$ for the LEDs based on 1:1 materials (Figure 3c). Also, the LED with the largest MAI excess (6:1) showed an enhanced radiance (maximum at $1.2 \mathrm{~W} \cdot \mathrm{Sr}^{-1} \cdot \mathrm{m}^{-2}$ ) and $\mathrm{EQE}(0.67 \%)$, despite the lower current density flowing through the device (Figure 3a). The EQE values recorded for the LED series follow 
the trend of the decay dynamics and PL intensities of the emissive layers, as described above. Interestingly, the electroluminescence spectra of the LEDs series (Figure S6) show a single emission peak, analogous to the PL spectra recorded for the series of compound after exposure to air (Figure S3b). We found the stability of the perovskite LEDs to be rather poor, several minutes in the best working devices, as observed in several reports on these devices. The typical low lifetime of perovskite LEDs can be ascribed to the limited stability of perovskites, as well as to the instability induced by the particular device operation. Under the relatively high applied bias, several effects such as ionic migration, ${ }^{35}$ diffusion of metallic species from electrodes, ${ }^{36-37}$ photoluminescence quenching, ${ }^{38}$ can take place. While perovskite solar cells are becoming more stable thanks also to material and encapsulation development, their stability is expected to be higher as the current density in typical perovskite solar cells is lower than in perovskite LEDs. In the latter, thermal stress due to Joule heating can accelerate the emitting layer degradation, especially for methylammonium-based perovskites. ${ }^{39}$ These limitations are, however, not fully understood and still under investigation.

In order to shed light on the improved optical and optoelectronic properties of the samples with excess MAI, we studied their PL dynamics as a function of the excitation density (Figure 4). For the 1:1 perovskite, as clearly observed in Figure 4a, the PL dynamics become slower as the excitation density increases up to a certain value. This behavior has been observed in previous studies and it has been attributed to trap filling. ${ }^{40-42}$ By further increasing the excitation density, the PL dynamics become faster (Figure $4 \mathrm{~b}$ ) due to higher order recombination processes. ${ }^{43}$ On the other hand, as shown in Figure S5, the PL dynamics of the MAPI films with MAI:PbI 2 ratio of 3:1 and 6:1 exhibit a different trend compared to the stoichiometric perovskite. Their PL dynamics become faster when increasing the excitation density, without any change in the trend as observed 
for the stoichiometric material. In order to better visualize the PL dynamics, the average PL lifetime is plotted as a function of the excitation density (Figure 4c) for the series of materials studied here. For the reference 1:1 MAPI, the excitation density at which the inversion in the behavior of the dynamics occurs (maximum of the graph in Figure 4c), provides an estimation of the trap density of the material. This value is approximately $2 \cdot 10^{18} \mathrm{~cm}^{-3}$, and is substantially larger compared to previous literature reports, where trap density in between $10^{16}$ and $10^{17} \mathrm{~cm}^{-3}$ were observed. ${ }^{12,44-46}$ The large trap density hence explains the low PLQY and in particular the poor EQE of the corresponding LEDs. The effect of these trap states remains puzzling, as the same 1:1 MAPI films do lead to very efficient solar cells (power conversion efficiency above $18 \%$ ), with photovoltage exceeding $1.1 \mathrm{~V} \cdot{ }^{47-48}$ Hence, traps may in fact be shallow such that under continued illumination carrier de-trapping is an efficient process. ${ }^{49}$ The physical nature of trap states in perovskite materials remains unclear. They likely originate from halide vacancies on the perovskite surface/grain boundaries, as reported in recently. ${ }^{50-51}$ Recently, it was shown that by combining light and atmospheric treatments it is possible to increase the internal luminescence quantum efficiencies of perovskite films from $1 \%$ to $90 \%,{ }^{52}$ a phenomenon analogous to what observed in our vacuum deposited MAPI films. The authors proposed that, as a result of $\mathrm{O}_{2}$ reduction to $\mathrm{O}_{2}{ }^{-}$at surface vacancies occupied by trapped electrons, the sub-gap (trap) states shift down into the valence band, effectively removing the trap states. The same effect might be occurring here, upon air exposure of the non-stoichiometric MAPI samples. 

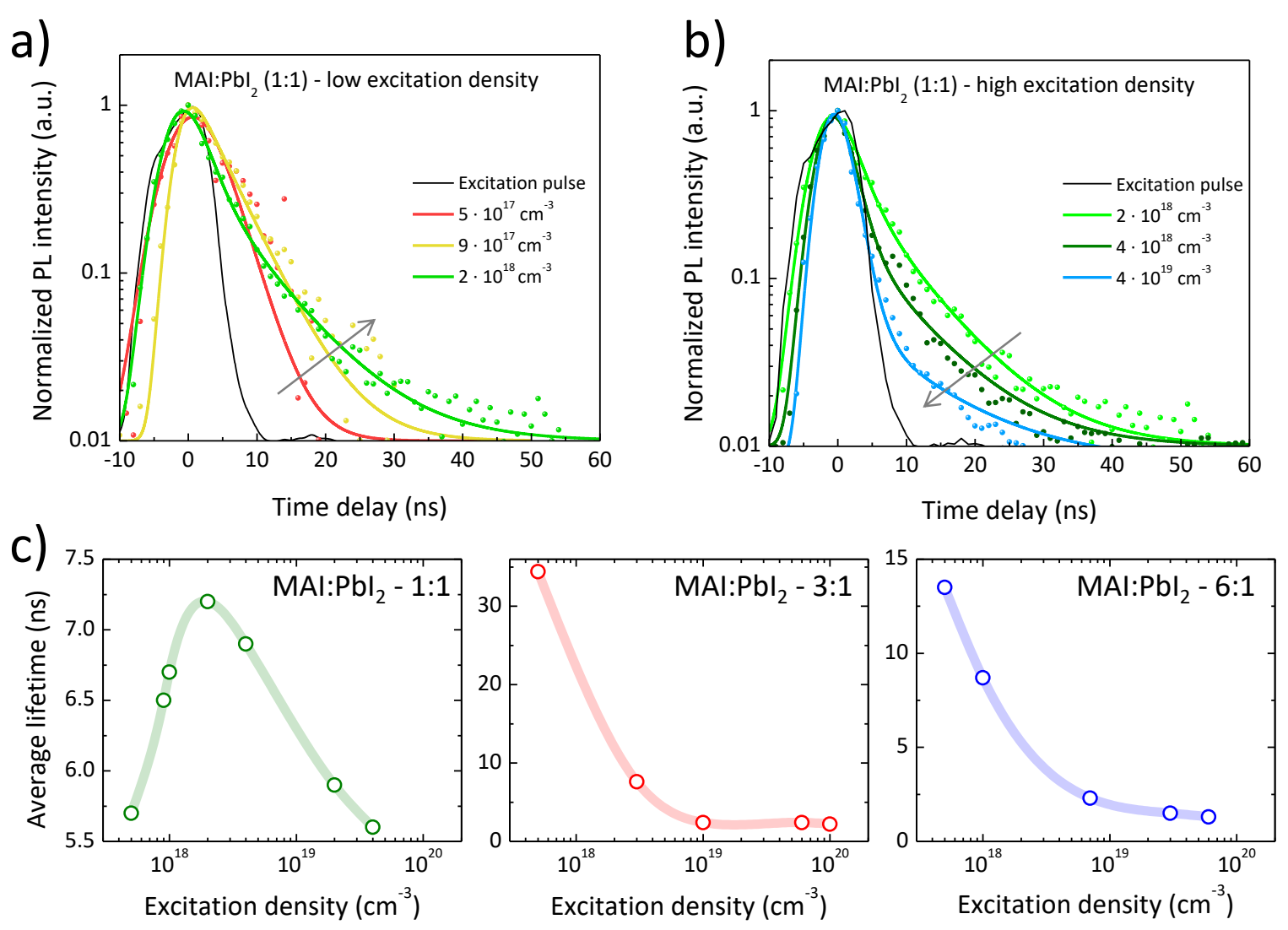

Figure 4. PL dynamics at a) low and b) high excitation densities for the MAPI film deposited with a MAI: $\mathrm{PbI}_{2}$ ratio of 1:1. Symbols are experimental data and lines are fits using a biexponential function. c) Trend of the average lifetime as a function of the excitation densities for materials with increasing MAI content. The samples were excited with $3 \mathrm{~ns}$ duration pulses at $520 \mathrm{~nm}$, and the dynamics were recorded at the wavelength of the maximum intensity of each sample.

Other processes might contribute to alter the perovskite (surface) chemistry during MAPI deposition at high MAI rate. Recent studies have highlighted the possibility of decomposition of MAI into compounds other than its precursors, methylamine and hydroiodic acid. ${ }^{53-54}$ The 
molecular salt MAI might decompose into energetically favored thermal degradation products, such as iodomethane and ammonia. Interestingly, iodomethane had been show to passivate the perovskite surface, increasing the grain size while reducing the trap density. ${ }^{55}$ However, further insight on the exact structural and chemical effects are necessary to rationalize these findings. ${ }^{56}$ On the other hand, both the films with MAI excess show a continuous decrease of the PL lifetime, indicating that traps are already filled in this excitation regime. Hence, the excess MAI efficiently passivates traps, reducing their concentration in comparison with the 1:1 MAPI. Importantly, the longest PL lifetime and reduced trap concentration agree with the trend observed in the EQE of the devices.

\section{CONCLUSION}

In summary, the effect of excess methylammonium iodide (MAI) in the preparation of vacuumdeposited methylammonium lead iodide (MAPI) thin films was studied. The stoichiometry was controlled by the relative deposition rates of $\mathrm{PbI}_{2}$ and $\mathrm{MAI}$ during the vacuum deposition process. We observed substantial differences in the perovskite films, with the PL intensity proportional to the MAI content. By studying the excitation density dependence of the photoluminescence lifetime, a large concentration of trap states was deduced for the stoichiometric MAPI films, which appears to be responsible for their low luminescence. The use of excess MAI in evaporated films is capable of efficiently passivating these traps, in analogy to what was observed for solutionprocessed MAPI films. Importantly, we were able to prepare planar light-emitting diodes with external quantum efficiency approaching $2 \%$ by using MAPI films with intentionally altered stoichiometry. This value is almost two orders of magnitude higher compared to the reference

LEDs employing the stoichiometric MAPI. The data presented here are promising for the 
development of efficient, vacuum-deposited perovskite LEDs, where trap management is essential in order to guarantee an efficient electroluminescence.

\section{ASSOCIATED CONTENT}

Supporting Information

The Supporting Information is available free of charge on the ACS Publications website at DOI: SEM images, optical absorption, PL spectra, PL decay kinetics and EL spectra for the samples discussed in the manuscript. Full experimental section.

\section{AUTHOR INFORMATION}

\section{Corresponding Authors}

*E-mail: michele.sessolo@uv.es

ORCID

Michele Sessolo: 0000-0002-9189-3005

\section{ACKNOWLEDGEMENTS}

We acknowledge financial support from the European Union H2020 project INFORM (grant 675867). F. P. acknowledges the European Union for his Marie Skłodowska-Curie Grant (PerovSAMs - 747599). N.D. and N.B. would like to acknowledge the Universities of Fribourg and Bern, Switzerland, for providing funding and infrastructure. Financial support is acknowledged from the Spanish Ministry of Economy and Competitiveness (MINECO) via the Unidad de Excelencia María de Maeztu MDM-2015-0538, MAT2017-88821-R, PCIN-2015-255, 
PCIN-2017-014 and the Generalitat Valenciana (Prometeo/2016/135). M.S. thanks the MINECO for his RyC contract.

\section{REFERENCES}

1. Sutherland, B. R.; Sargent, E. H. Perovskite Photonic Sources. Nat. Photon. 2016, 10, 295-302.

2. Kim, Y.-H.; Cho, H.; Lee, T.-W. Metal Halide Perovskite Light Emitters. Proc. Natl. Acad. Sci. U.S.A. 2016, 113 (42), 11694-11702.

3. Veldhuis, S. A.; Boix, P. P.; Yantara, N.; Li, M.; Sum, T. C.; Mathews, N.; Mhaisalkar, S. G. Perovskite Materials for Light-Emitting Diodes and Lasers. Adv. Mater. 2016, 28 (32), 68046834.

4. Kitazawa, N.; Watanabe, Y.; Nakamura, Y. Optical Properties of $\mathrm{CH}_{3} \mathrm{NH}_{3} \mathrm{PbX}_{3}(\mathrm{X}=$ Halogen) and Their Mixed-Halide Crystals. J. Mater. Sci. 2002, 37 (17), 3585-3587.

5. Noh, J. H.; Im, S. H.; Heo, J. H.; Mandal, T. N.; Seok, S. I. Chemical Management for Colorful, Efficient, and Stable Inorganic-Organic Hybrid Nanostructured Solar Cells. Nano Lett. 2013, $13(4), 1764-1769$.

6. Comin, R.; Walters, G.; Thibau, E. S.; Voznyy, O.; Lu, Z.-H.; Sargent, E. H. Structural, Optical, and Electronic Studies of Wide-Bandgap Lead Halide Perovskites. J. Mater. Chem. C 2015, 3 (34), 8839-8843.

7. Sessolo, M.; Gil-Escrig, L.; Longo, G.; Bolink, H. J. Perovskite Luminescent Materials. Top. Curr. Chem. 2016, 374 (4), 52.

8. Chondroudis, K.; Mitzi, D. B. Electroluminescence from an Organic-Inorganic Perovskite Incorporating a Quaterthiophene Dye within Lead Halide Perovskite Layers. Chem. Mater. 1999, 11 (11), 3028-3030.

9. Xing, G.; Mathews, N.; Sun, S.; Lim, S. S.; Lam, Y. M.; Gratzel, M.; Mhaisalkar, S.; Sum, T. C. Long-Range Balanced Electron- and Hole-Transport Lengths in Organic-Inorganic $\mathrm{CH}_{3} \mathrm{NH}_{3} \mathrm{Pbl}_{3}$. Science 2013, 342 (6156), 344-347.

10. Stranks, S. D.; Burlakov, V. M.; Leijtens, T.; Ball, J. M.; Goriely, A.; Snaith, H. J. Recombination Kinetics in Organic-Inorganic Perovskites: Excitons, Free Charge, and Subgap States. Phys. Rev. Appl. 2014, 2 (3), 034007.

11. Wehrenfennig, C.; Eperon, G. E.; Johnston, M. B.; Snaith, H. J.; Herz, L. M. High Charge Carrier Mobilities and Lifetimes in Organolead Trihalide Perovskites. Adv. Mater. 2014, 26 (10), 1584-1589.

12. Xing, G.; Mathews, N.; Lim, S. S.; Yantara, N.; Liu, X.; Sabba, D.; Grätzel, M.; Mhaisalkar, S.; Sum, T. C. Low-Temperature Solution-Processed Wavelength-Tunable Perovskites for Lasing. Nat. Mater. 2014, 13 (5), 476-480.

13. Lin, Q.; Armin, A.; Nagiri, R. C. R.; Burn, P. L.; Meredith, P. Electro-Optics of Perovskite Solar Cells. Nat. Photon. 2014, 9, 106.

14. Savenije, T. J.; Ponseca, C. S.; Kunneman, L.; Abdellah, M.; Zheng, K.; Tian, Y.; Zhu, Q.; Canton, S. E.; Scheblykin, I. G.; Pullerits, T.; Yartsev, A.; Sundström, V. Thermally Activated Exciton 
Dissociation and Recombination Control the Carrier Dynamics in Organometal Halide Perovskite. J. Phys. Chem. Lett. 2014, 5 (13), 2189-2194.

15. Yang, Y.; Yang, M.; Li, Z.; Crisp, R.; Zhu, K.; Beard, M. C. Comparison of Recombination Dynamics in $\mathrm{CH}_{3} \mathrm{NH}_{3} \mathrm{PbBr}_{3}$ and $\mathrm{CH}_{3} \mathrm{NH}_{3} \mathrm{Pbl}_{3}$ Perovskite Films: Influence of Exciton Binding Energy. J. Phys. Chem. Lett. 2015, 6 (23), 4688-4692.

16. Deschler, F.; Price, M.; Pathak, S.; Klintberg, L. E.; Jarausch, D.-D.; Higler, R.; Hüttner, S.; Leijtens, T.; Stranks, S. D.; Snaith, H. J.; Atatüre, M.; Phillips, R. T.; Friend, R. H. High Photoluminescence Efficiency and Optically Pumped Lasing in Solution-Processed Mixed Halide Perovskite Semiconductors. J. Phys. Chem. Lett. 2014, 5 (8), 1421-1426.

17. Wu, X.; Trinh, M. T.; Niesner, D.; Zhu, H.; Norman, Z.; Owen, J. S.; Yaffe, O.; Kudisch, B. J.; Zhu, X. Y. Trap States in Lead lodide Perovskites. J. Am. Chem. Soc. 2015, 137 (5), 2089-2096.

18. Cho, H.; Jeong, S.-H.; Park, M.-H.; Kim, Y.-H.; Wolf, C.; Lee, C.-L.; Heo, J. H.; Sadhanala, A.; Myoung, N.; Yoo, S.; Im, S. H.; Friend, R. H.; Lee, T.-W. Overcoming the Electroluminescence Efficiency Limitations of Perovskite Light-Emitting Diodes. Science 2015, 350 (6265), 12221225.

19. Yuan, M.; Quan, L. N.; Comin, R.; Walters, G.; Sabatini, R.; Voznyy, O.; Hoogland, S.; Zhao, Y.; Beauregard, E. M.; Kanjanaboos, P.; Lu, Z.; Kim, D. H.; Sargent, E. H. Perovskite Energy Funnels for Efficient Light-Emitting Diodes. Nat. Nanotechnol. 2016, 11 (10), 872-877.

20. Tian, Y.; Zhou, C.; Worku, M.; Wang, X.; Ling, Y.; Gao, H.; Zhou, Y.; Miao, Y.; Guan, J.; Ma, B. Highly Efficient Spectrally Stable Red Perovskites Light-Emitting Diodes. Adv. Mater. 2017.

21. Wang, J.; Wang, N.; Jin, Y.; Si, J.; Tan, Z.-K.; Du, H.; Cheng, L.; Dai, X.; Bai, S.; He, H.; Ye, Z.; Lai, M. L.; Friend, R. H.; Huang, W. Interfacial Control Toward Efficient and Low-Voltage Perovskite Light-Emitting Diodes. Adv. Mater. 2015, 27 (14), 2311-2316.

22. Sadhanala, A.; Ahmad, S.; Zhao, B.; Giesbrecht, N.; Pearce, P. M.; Deschler, F.; Hoye, R. L. Z.; Gödel, K. C.; Bein, T.; Docampo, P.; Dutton, S. E.; De Volder, M. F. L.; Friend, R. H. Blue-Green Color Tunable Solution Processable Organolead Chloride-Bromide Mixed Halide Perovskites for Optoelectronic Applications. Nano Lett. 2015, 15 (9), 6095-6101.

23. Ham, S.; Choi, Y. J.; Lee, J.-W.; Park, N.-G.; Kim, D. Impact of Excess CH3NH3I on Free Carrier Dynamics in High-Performance Nonstoichiometric Perovskites. The Journal of Physical Chemistry C 2017, 121 (5), 3143-3148.

24. Lee, J.-W.; Choi, Y. J.; Yang, J.-M.; Ham, S.; Jeon, S. K.; Lee, J. Y.; Song, Y.-H.; Ji, E. K.; Yoon, D.H.; Seo, S.; Shin, H.; Han, G. S.; Jung, H. S.; Kim, D.; Park, N.-G. In-Situ Formed Type I Nanocrystalline Perovskite Film for Highly Efficient Light-Emitting Diode. ACS Nano 2017, 11 (3), 3311-3319.

25. Ham, S.; Choi, Y. J.; Lee, J.-W.; Park, N.-G.; Kim, D. Impact of Excess $\mathrm{CH}_{3} \mathrm{NH}_{3}$ I on Free Carrier Dynamics in High-Performance Nonstoichiometric Perovskites. J. Phys. Chem. C 2017, 121 (5), 3143-3148.

26. Liu, M.; Johnston, M. B.; Snaith, H. J. Efficient Planar Heterojunction Perovskite Solar Cells by Vapour Deposition. Nature 2013, 501, 395.

27. Eperon, G. E.; Habisreutinger, S. N.; Leijtens, T.; Bruijnaers, B. J.; Van Franeker, J. J.; Dequilettes, D. W.; Pathak, S.; Sutton, R. J.; Grancini, G.; Ginger, D. S.; Janssen, R. A. J.; Petrozza, A.; Snaith, H. J. The Importance of Moisture in Hybrid Lead Halide Perovskite Thin Film Fabrication. ACS Nano 2015, 9 (9), 9380-9393. 
28. Brenes, R.; Guo, D.; Osherov, A.; Noel, N. K.; Eames, C.; Hutter, E. M.; Pathak, S. K.; Niroui, F.; Friend, R. H.; Islam, M. S.; Snaith, H. J.; Bulović, V.; Savenije, T. J.; Stranks, S. D. Metal Halide Perovskite Polycrystalline Films Exhibiting Properties of Single Crystals. Joule 1 (1), 155-167.

29. Dong, X.; Fang, X.; Lv, M.; Lin, B.; Zhang, S.; Ding, J.; Yuan, N. Improvement of the Humidity Stability of Organic-Inorganic Perovskite Solar Cells Using Ultrathin $\mathrm{Al}_{2} \mathrm{O}_{3}$ Layers Prepared by Atomic Layer Deposition. J. Mater. Chem. A 2015, 3 (10), 5360-5367.

30. Niu, G.; Li, W.; Meng, F.; Wang, L.; Dong, H.; Qiu, Y. Study on the Stability of $\mathrm{CH}_{3} \mathrm{NH}_{3} \mathrm{Pbl}_{3}$ Films and the Effect of Post-Modification by Aluminum Oxide in All-Solid-State Hybrid Solar Cells. J. Mater. Chem. A 2014, 2 (3), 705-710.

31. Bass, K. K.; McAnally, R. E.; Zhou, S.; Djurovich, P. I.; Thompson, M. E.; Melot, B. C. Influence of Moisture on the Preparation, Crystal Structure, and Photophysical Properties of Organohalide Perovskites. Chem. Commun. 2014, 50 (99), 15819-15822.

32. Park, B.-w.; Jain, S. M.; Zhang, X.; Hagfeldt, A.; Boschloo, G.; Edvinsson, T. Resonance Raman and Excitation Energy Dependent Charge Transfer Mechanism in Halide-Substituted Hybrid Perovskite Solar Cells. ACS Nano 2015, 9 (2), 2088-2101.

33. Mamun, A. A.; Ava, T. T.; Jeong, H. J.; Jeong, M. S.; Namkoong, G. A Deconvoluted PL Approach to Probe the Charge Carrier Dynamics of the Grain Interior and Grain Boundary of a Perovskite Film for Perovskite Solar Cell Applications. Physical Chemistry Chemical Physics 2017, 19 (13), 9143-9148.

34. Song, Z.; Watthage, S. C.; Phillips, A. B.; Tompkins, B. L.; Ellingson, R. J.; Heben, M. J. Impact of Processing Temperature and Composition on the Formation of Methylammonium Lead lodide Perovskites. Chemistry of Materials 2015, 27 (13), 4612-4619.

35. Li, C.; Guerrero, A.; Zhong, Y.; Gräser, A.; Luna, C. A. M.; Köhler, J.; Bisquert, J.; Hildner, R.; Huettner, $\mathrm{S}$. Real-Time Observation of Iodide Ion Migration in Methylammonium Lead Halide Perovskites. Small 2017, 13 (42), 1701711.

36. Domanski, K.; Correa-Baena, J.-P.; Mine, N.; Nazeeruddin, M. K.; Abate, A.; Saliba, M.; Tress, W.; Hagfeldt, A.; Grätzel, M. Not All That Glitters Is Gold: Metal-Migration-Induced Degradation in Perovskite Solar Cells. ACS Nano 2016, 10 (6), 6306-6314.

37. Seo, H.-K.; Kim, H.; Lee, J.; Park, M.-H.; Jeong, S.-H.; Kim, Y.-H.; Kwon, S.-J.; Han, T.-H.; Yoo, S.; Lee, T.-W. Efficient Flexible Organic/Inorganic Hybrid Perovskite Light-Emitting Diodes Based on Graphene Anode. Adv. Mater. 2017, 29 (12), 1605587.

38. Chen, S.; Wen, X.; Sheng, R.; Huang, S.; Deng, X.; Green, M. A.; Ho-Baillie, A. Mobile Ion Induced Slow Carrier Dynamics in Organic-Inorganic Perovskite CH3NH3PbBr3. ACS Appl. Mater. Interfaces 2016, 8 (8), 5351-5357.

39. Cho, H.; Kim, Y.-H.; Wolf, C.; Lee, H.-D.; Lee, T.-W. Improving the Stability of Metal Halide Perovskite Materials and Light-Emitting Diodes. Adv. Mater., 1704587.

40. Yamada, Y.; Yamada, T.; Shimazaki, A.; Wakamiya, A.; Kanemitsu, Y. Interfacial Charge-Carrier Trapping in $\mathrm{CH}_{3} \mathrm{NH}_{3} \mathrm{Pbl}_{3}$-Based Heterolayered Structures Revealed by Time-Resolved Photoluminescence Spectroscopy. J. Phys. Chem. Lett. 2016, 7 (11), 1972-1977.

41. Phuong, L. Q.; Braly, I. L.; Katahara, J. K.; Hillhouse, H. W.; Kanemitsu, Y. Nonlinear Photocarrier Recombination Dynamics in Mixed-Halide $\mathrm{CH}_{3} \mathrm{NH}_{3} \mathrm{~Pb}\left(\mathrm{I}_{1-\mathrm{x}} \mathrm{Br}_{\mathrm{x}}\right)_{3}$ Perovskite Thin Films. Appl. Phys. Express 2017, 10, 102401.

42. Handa, T.; Tex, D. M.; Shimazaki, A.; Wakamiya, A.; Kanemitsu, Y. Charge Injection Mechanism at Heterointerfaces in $\mathrm{CH}_{3} \mathrm{NH}_{3} \mathrm{Pbl}_{3}$ Perovskite Solar Cells Revealed by 
Simultaneous Time-Resolved Photoluminescence and Photocurrent Measurements. J. Phys. Chem. Lett. 2017, 8 (5), 954-960.

43. Saba, M.; Cadelano, M.; Marongiu, D.; Chen, F.; Sarritzu, V.; Sestu, N.; Figus, C.; Aresti, M.; Piras, R.; Geddo Lehmann, A.; Cannas, C.; Musinu, A.; Quochi, F.; Mura, A.; Bongiovanni, G. Correlated Electron-Hole Plasma in Organometal Perovskites. Nat. Commun. 2014, 5, 5049.

44. Manser, J. S.; Kamat, P. V. Band Filling with Free Charge Carriers in Organometal Halide Perovskites. Nat. Photon. 2014, 8 (9), 737-743.

45. Draguta, S.; Thakur, S.; Morozov, Y. V.; Wang, Y.; Manser, J. S.; Kamat, P. V.; Kuno, M. Spatially Non-uniform Trap State Densities in Solution-Processed Hybrid Perovskite Thin Films. J. Phys. Chem. Lett. 2016, 715-721.

46. de Quilettes, D. W.; Vorpahl, S. M.; Stranks, S. D.; Nagaoka, H.; Eperon, G. E.; Ziffer, M. E.; Snaith, H. J.; Ginger, D. S. Impact of Microstructure on Local Carrier Lifetime in Perovskite Solar Cells. Science 2015, 348 (6235), 683-686.

47. Momblona, C.; Gil-Escrig, L.; Bandiello, E.; Hutter, E. M.; Sessolo, M.; Lederer, K.; BlochwitzNimoth, J.; Bolink, H. J. Efficient Vacuum Deposited p-i-n and n-i-p Perovskite Solar Cells Employing Doped Charge Transport Layers. Energy Environ. Sci. 2016, 9 (11), 3456-3463.

48. Pérez-del-Rey, D.; Boix, P. P.; Sessolo, M.; Hadipour, A.; Bolink, H. J. Interfacial Modification for High-Efficiency Vapor-Phase-Deposited Perovskite Solar Cells Based on a Metal Oxide Buffer Layer. J. Phys. Chem. Lett. 2018, 9 (5), 1041-1046.

49. Chirvony, V. S.; González-Carrero, S.; Suárez, I.; Galian, R. E.; Sessolo, M.; Bolink, H. J.; Martínez-Pastor, J. P.; Pérez-Prieto, J. Delayed Luminescence in Lead Halide Perovskite Nanocrystals. J. Phys. Chem. C 2017, 121 (24), 13381-13390.

50. Abdi-Jalebi, M.; Andaji-Garmaroudi, Z.; Cacovich, S.; Stavrakas, C.; Philippe, B.; Richter, J. M.; Alsari, M.; Booker, E. P.; Hutter, E. M.; Pearson, A. J.; Lilliu, S.; Savenije, T. J.; Rensmo, H.; Divitini, G.; Ducati, C.; Friend, R. H.; Stranks, S. D. Maximizing and stabilizing luminescence from halide perovskites with potassium passivation. Nature 2018, 555, 497.

51. Azpiroz, J. M.; Mosconi, E.; Bisquert, J.; De Angelis, F. Defect migration in methylammonium lead iodide and its role in perovskite solar cell operation. Energy Environ. Sci. 2015, 8 (7), 2118-2127.

52. Brenes, R.; Guo, D.; Osherov, A.; Noel, N. K.; Eames, C.; Hutter, E. M.; Pathak, S. K.; Niroui, F.; Friend, R. H.; Islam, M. S.; Snaith, H. J.; Bulović, V.; Savenije, T. J.; Stranks, S. D. Metal Halide Perovskite Polycrystalline Films Exhibiting Properties of Single Crystals. Joule 2017, 1 (1), 155167.

53. Juarez-Perez, E. J.; Hawash, Z.; Raga, S. R.; Ono, L. K.; Qi, Y. Thermal degradation of $\mathrm{CH} 3 \mathrm{NH} 3 \mathrm{PbI} 3$ perovskite into $\mathrm{NH} 3$ and $\mathrm{CH} 3$ I gases observed by coupled thermogravimetrymass spectrometry analysis. Energy \& Environmental Science 2016, 9 (11), 3406-3410.

54. Olthof, S.; Meerholz, K. Substrate-dependent electronic structure and film formation of $\mathrm{MAPbl}_{3}$ perovskites. Sci. Rep. 2017, 7, 40267.

55. Xu, W.; McLeod, J. A.; Yang, Y.; Wang, Y.; Wu, Z.; Bai, S.; Yuan, Z.; Song, T.; Wang, Y.; Si, J.; Wang, R.; Gao, X.; Zhang, X.; Liu, L.; Sun, B. lodomethane-mediated organometal halide perovskite with record photoluminescence lifetime. ACS Applied Materials and Interfaces 2016, 8 (35), 23181-23189.

56. Liu, L.; Mcleod, J. A.; Wang, R.; Shen, P.; Duhm, S. Tracking the formation of methylammonium lead triiodide perovskite. Applied Physics Letters 2015, 107 (6), 061904. 
Table of Contents Graphic

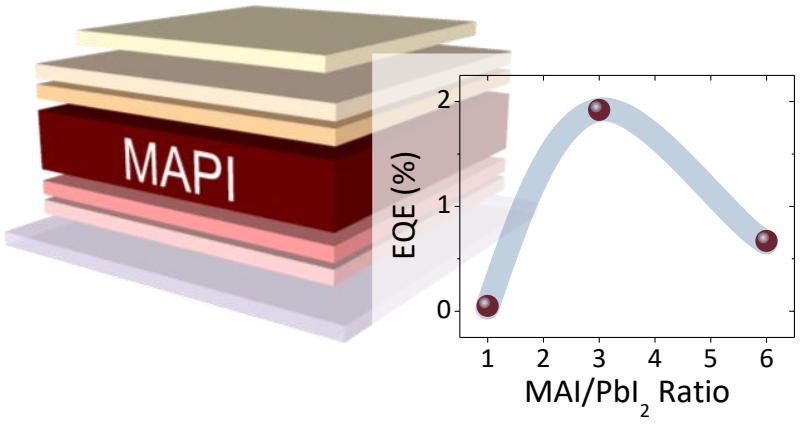

